\title{
IDENTIFIKASI PRODUK TURUNAN HYDROPROCESSING MODEL MINYAK SINTETIS BATUBARA MENGGUNAKAN GC-FID/NPD/MS
}

\author{
Muhammad Hanif $^{1)}$ Yusnitati $^{1)}$, dan Nasikin Nataadmadja ${ }^{2)}$ \\ ${ }^{1)}$ Pusat Teknologi Pengembangan Sumberdaya Energi \\ BPPT Gedung II Lantai $22 \mathrm{JI}$ MH Thamrin 8 Jakarta 10340 \\ 2) Jurusan Teknik Kimia FTUI Kampus UI Depok \\ E-mail: muhammad.hanif@bppt.go.id
}

\begin{abstract}
An analysis of identifying a derivative product of liquefied coal model hydroprocessing was conducted. For that purpose, an integration gas chromatography flame ionization-nitrogen phosphorous detector and mass spectrometry (GC-FID/NPD/MS) was used. Hydroprocessing process was performed by vibrating micro autoclave tipe batch using Ni-W/Alumina catalyst under initial hydrogen pressure $6 \mathrm{MPa}$, reaction temperature $375^{\circ} \mathrm{C}$ and one hour retention time. The analysis result showed that the predominant reaction were hydrogenation, hydrodenitrogenation (HDN) and hydrodeoxygenation (HDO). The HDO of methyl phenol and ethyl phenol took place faster than the other hydroprocessing reactions such as HDN of quinoline and aromatic hydrogenation (butyl benzene, naphthalene, phenanthrene dan pyrene). This indicates that the hydrogenation reaction or the cleavage of $\mathrm{C}-\mathrm{O}$ bonding took place very fast that alkyl could not be detected in the oil. The HDN reaction or the cleavage of $C-N$ took place slower but the the nitrogen containing compound vanished faster due to selective adsorption of the catalyst. However the hydrogenation reaction of mono-aromatic took place faster than poly-aromatic
\end{abstract}

Kata kunci: gas chromatography, identifikasi senyawa, model minyak sintetis

\section{PENDAHULUAN}

Teknologi hydroprocessing telah lama digunakan dalam pemurnian minyak bumi. Teknologi ini juga dapat diaplikasikan untuk meningkatkan kualitas dari minyak sintetis batubara sehingga dihasilkan bahan bakar yang bersih dan memenuhi persyaratan perlindungan lingkungan global.

Namun demikian, minyak bumi yang bersifat alifatik berbeda dari minyak sintetis dari batubara yang banyak mengandung senyawa-senyawa hidrokarbon aromatis (mono- dan poly- aromatis) dan heteroatom yang terikat pada komponen aromatik, khususnya nitrogen dalam fraksi basa dan polar serta oksigen dalam fraksi asam. Sehingga, proses hydroprocessing minyak sintetis batubara lebih difokuskan pada proses hidrogenasi untuk menurunkan kandungan senyawa-senyawa hidrokarbon aromatis, dan proses hidrodenitrogenasi-hidrodeoksigenasi untuk menghilangkan senyawa-senyawa heteroatom.

Karena minyak sintetis batubara memiliki struktur dan senyawa yang komplek, maka pengujian pada proses hydroprocessing dapat dilakukan melalui metode pendekatan model senyawa. Dari pendekatan ini diharapkan dapat diprediksi karakteristik dan skema reaksi yang terjadi jika digunakan bahan baku dan kondisi yang sesungguhnya. Oleh karena itu, model senyawa yang diuji harus dipilih serepresentatif mungkin dengan bahan baku sesungguhnya.

Beberapa peneliti telah melakukan studi aktivitas hidrodeoksigenasi model minyak sintetis batubara menggunakan senyawa methyl phenol (Odebunmi E.O, 1983) dan ethyl phenol [Aubert C, 1988]. Pada penelitian lain, dikaji reaktifitas model senyawa quinoline (Eijsbouts S, 1991) dalam proses hidrodenitrogenasi. Sedangkan, untuk mengetahui mekanisme reaksi senyawa hidrokarbon aromatis dalam proses hidrogenasi diwakili oleh model senyawa poly-aromatics naphthalene, phenanthrene (Lee, C.L, 1987), pyrene (Anderson J.R., 1996) dan monoaromatis butyl benzene (Moreau, 1988).

Masih sedikit penelitian yang dilakukan untuk mengkaji proses hydroprocessing minyak sintetis batubara secara simultan, dimana semua model senyawa yang mewakili minyak sintetis batubara 
diuji dalam bentuk campuran, sehingga dapat diketahui reaktifitas masing-masing model senyawa terhadap kompetitif adsorpsi pada fase aktifnya dan pengaruh keberadaan produk inorganik, seperti $\mathrm{H}_{2} \mathrm{~S}, \mathrm{NH}_{3}, \mathrm{H}_{2} \mathrm{O}$ terhadap laju reaksi secara keseluruhan.

Umumnya pengujian tersebut difokuskan pada proses hydroprocessing secara individu, misalnya HYD, HDN, HDO atau HDS, seperti ditunjukkan pada Gambar 1.

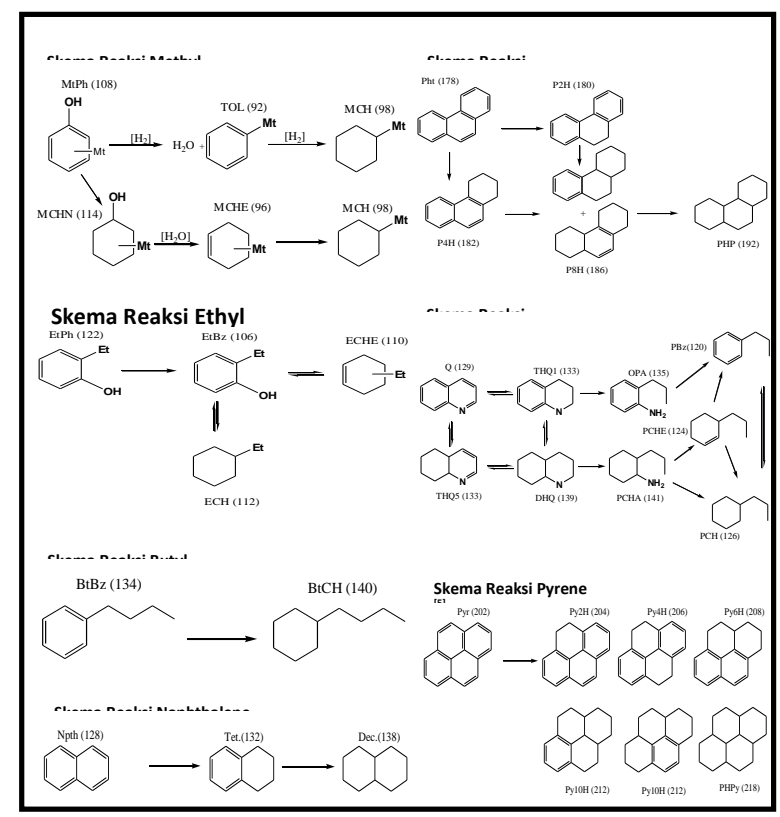

Gambar 1. Skema Reaksi Individu Model Minyak Batubara Cair

Untuk menunjang studi ini, beberapa teknik analisis telah dikembangkan dalam mengidentifikasi komposisi senyawa dan mengetahui produk turunannya dari suatu reaksi, antara lain high performance liquid chromatography (HPLC), gas chromatography, dan nuklear magnetic resonance $\left({ }^{13} \mathrm{C}-\mathrm{NMR}\right)$.

Dari latar belakang di atas, maka tulisan ini membahas hasil pengujian campuran model senyawa yang mewakili senyawa-senyawa dalam minyak sintetis batubara pada proses hydroprocessing menggunakan vibrating microautoclave tipe batch dengan katalis $\mathrm{Ni}$ W/Alumina pada tekanan awal $6 \mathrm{MPa}$, temperatur reaksi $375^{\circ} \mathrm{C}$ selama 1 jam. Produk turunan dari campuran model senyawa tersebut diidentifikasi dengan membandingkan laju reaksi dari masing-masing senyawa dalam proses hidrogenasi, hidrodeoksigenasi dan hidrodenitrogenasi menggunakan teknik analisis integrasi gas chromatography flame ionizationnitrogen phosphorous detector dan mass spectrometry (GC-FID/NPD/MS).

\section{BAHAN DAN METODE}

\subsection{Model Minyak Batubara Cair}

Semua senyawa yang digunakan sebagai model minyak batubara cair adalah senyawa komersial dan digunakan tanpa pemurnian. Senyawasenyawa tersebut dicampurkan dengan presentase sebagai berikut $15 \%$ berat 4-methyl phenol (prod. Nacalai Tesque), $5 \%$ berat 3-ethyl phenol (prod. Tokyo Kasei), $10 \%$ berat butyl benzene (prod. Tokyo Kasei), 10\% berat naphthalene (prod. Nacalai Tesque), $5 \%$ berat phenanthrene (prod.Tokyo Kasei), 5\% berat pyrene (prod. Tokyo Kasei), 5\% berat quinoline (prod. Nakarai Chem.). Selain itu, juga ditambahkan $40 \%$ berat isooctane sebagai pelarut dan $5 \%$ berat tetradecane sebagai senyawa referensi dalam analisis. Isooctane and tetradecane dipilih sebagai pelarut dan senyawa referensi karena waktu retensi senyawa-senyawa ini dan produknya secara sempurna berbeda dari senyawa yang akan dideteksi, sehingga dapat memberikan resolusi yang baik dalam analisis.

\subsection{Katalis}

Katalis nickel-tungsten (Ni-W) berpenyangga alumina $\left(\mathrm{Al}_{2} \mathrm{O}_{3}\right)$ dengan komposisi $\mathrm{NiO} 4,2 \%$ berat, $\mathrm{WO}_{3} 29,2 \%$ berat dan luas permukaan $167 \mathrm{~m}^{2} / \mathrm{gr}$ dikalsinasi pada temperatur $400^{\circ} \mathrm{C}$ selama 2 jam. Selanjutnya, dilakukan proses sulfidasi di dalam image furnace dengan mengalirkan campuran gas $\mathrm{H}_{2} \mathrm{~S} / \mathrm{H}_{2}(10 \%$ vol, 80 $\mathrm{ml} / \mathrm{min}$ ) selama 1,5 jam dari temperatur ruang sampai temperatur $400^{\circ} \mathrm{C}$ dan dipertahankan selama 2 jam pada temperatur $400^{\circ} \mathrm{C}$, kemudian didinginkan hingga temperatur ruang. Katalis yang telah mengalami proses sulfidasi ditempatkan dalam desikator untuk mencegah teroksidasi kembali oleh udara dan kemudian diisikan ke dalam reaktor.

Proses kalsinasi dilakukan untuk membentuk interaksi dan dispersi yang tinggi antara katalis $\mathrm{WO}_{3}$ dengan permukaan penyangga $\mathrm{Al}_{2} \mathrm{O}_{3}$, sehingga dapat meningkatkan kemampuan katalis untuk di sulfidasi (sulfidability). Sedangkan, proses sulfidasi dilakukan untuk membentuk fase aktif katalis sulfida.

\subsection{Metode Pengujian}

Untuk mengidentifikasi senyawa produk dari model minyak batubara cair, maka dilakukan proses hydroprocessing di dalam vibrating micro autoclave yang dilengkapi quartz-glass container bervolume $35 \mathrm{ml}$ dan furnace yang terdiri dari 4 lubang tempat reaktor, seperti ditunjukkan pada Gambar 2.

Sebelum reaksi, 0,25 gram katalis $\mathrm{Ni}$ W/Alumina tersulfidasi dan $5 \mathrm{ml}$ campuran 
senyawa model minyak batubara cair dimasukkan dalam quartz-glass container dan ditempatkan dalam reaktor stain. steel. Reaktor tersebut dimasukkan ke dalam lubang electric furnace dengan mengatur ketepatan posisi termokopel. Sebelum reaksi, reaktor dibilas dengan hidrogen untuk menghilangkan udara. Jika tak terjadi kebocaran, maka gas hidrogen diinjeksi pada tekanan awal $6 \mathrm{MPa}$ (cold charge). Selanjutnya, temperatur furnace diatur sesuai dengan temperatur pengujian yaitu $375{ }^{\circ} \mathrm{C}$. Waktu reaksi dihitung dari titik dimana reaktor ditempatkan ke dalam dinding tungku. Reaktor digerakkan dengan motor selama reaksi berlangsung. Setelah 1 jam, reaktor diangkat dari tungku dan didinginkan.

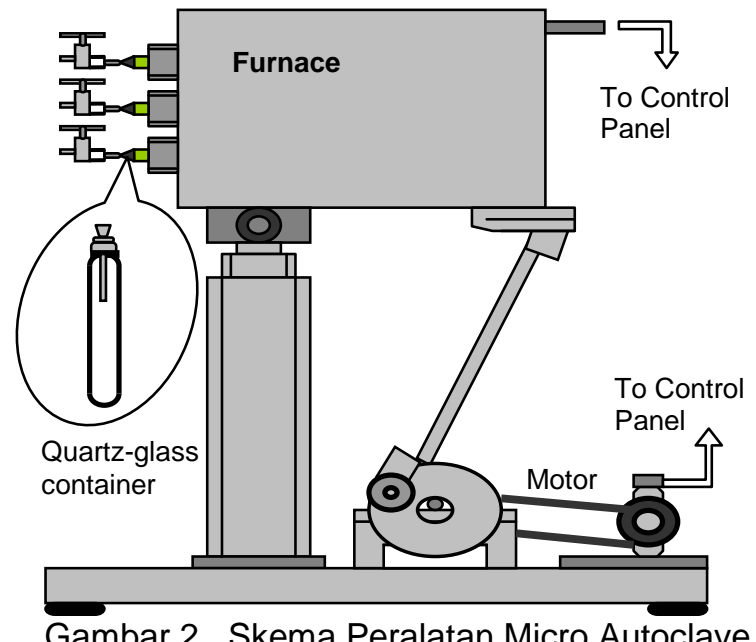

\subsection{Metode Analisis}

Produk cair dari autoclaf difiltrasi secara vakum. Sebelum analisis, sampel tersebut diencerkan dalam larutan acetone dengan menginjeksi 100 $\mu$ sampel dan $1000 \mu$ l acetone ke dalam botol analisis menggunakan tube syringe.

Pada tahap awal, dilakukan analisis distribusi peak pada masing-masing senyawa menggunakan temperature-programmed HP 5890 Series II GC dengan kolom ultra performance capillary berukuran $50 \mathrm{~m} \times 0.2 \mathrm{~mm}$ x $0.33 \mu \mathrm{m}$ (crosslinked methyl siloxane) yang dilengkapi automatic sampler HP 7673. Peralatan analisis ini mempunyai dua signal detektor yaitu flame ionization detector (FID) dan nitrogen phosphorous detector (NPD). Detektor NPD digunakan untuk mengkonfirmasi hasil identifikasi dari FID khusus dugunakan untuk senyawasenyawa nitrogen.

Selanjutnya, untuk mengetahui jenis senyawa dan berat molekulnya, maka dilakukan analisis menggunakan GC-Mass Spectroscopy HP 6890 Series GC system yang dilengkapi mass selective detector HP 5973. Kolom kapiler yang digunakan untuk pemisahan produk adalah ultra performance capillary $50 \mathrm{~m}$ x $0.2 \mathrm{~mm} \times 0.33$ $\mu \mathrm{m}$ film thickness (crosslinked methyl siloxane). Helium sebagai gas elusi. Analisis dilakukan pada kondisi sebagai berikut: temperatur awal $50^{\circ} \mathrm{C}$, waktu awal 1 menit, temperatur akhir 300 ${ }^{\circ} \mathrm{C}$, waktu akhir 9.67 menit, kecepatan pemanasan $5 \mathrm{deg} / \mathrm{min}$, temperatur oven $50^{\circ} \mathrm{C}$, temperatur injeksi $280^{\circ} \mathrm{C}$, temperatur detektor $300^{\circ} \mathrm{C}$, waktu kesetimbangan 1 menit. Total waktu analisis adalah 70 menit. Semua hasil identifikasi akan ditunjukkan pada komputer yang dihubungkan secara on-line dan didukung oleh program software dan basis data untuk semua kondisi pengujian dan senyawa yang dianalisis.

\section{HASIL PENELITIAN DAN DISKUSI}

\subsection{Identifikasi Senyawa}

Gambar 3 menunjukkan hasil identifikasi peak dari distribusi produk hydroprocessing model minyak sintetis batubara menggunakan detektor FID pada temperatur reaksi $375^{\circ} \mathrm{C}$. Hasil identifikasi peak pada detektor NPD digunakan sebagai konfirmasi, khususnya untuk analisis senyawa nitrogen dari hasil identifikasi peak FID karena isooctane dan aceton digunakan sebagai pelarut. Begitu pula peak untuk tetradecane sebagai senyawa referensi yang muncul sebelum hidrogenasi produk phenantherene dan pyrene.

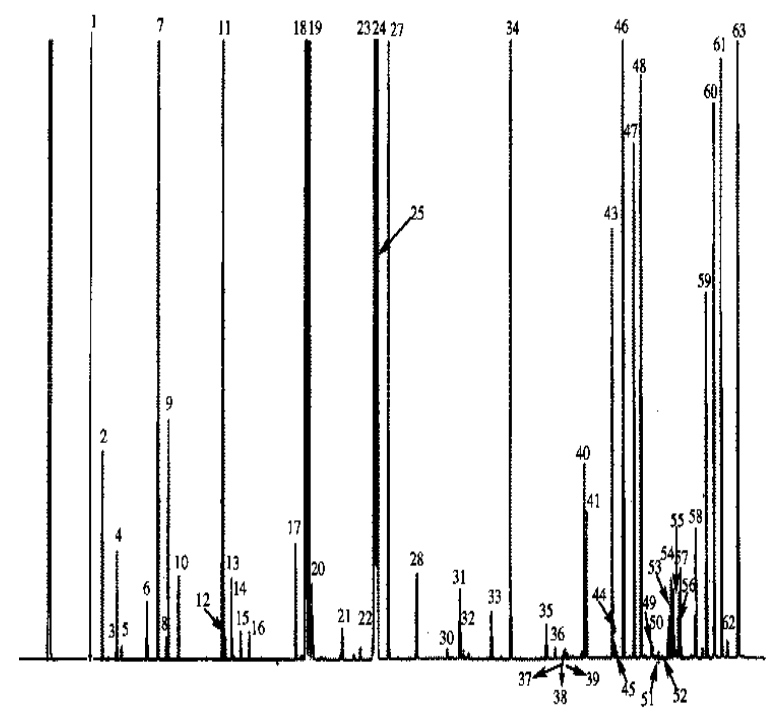

Gambar 3. Hasil analisis GC-FID peak dari distribusi produk hydroprocessing model minyak batubara

Turunan produk methyl phenol (methyl cyclohexane, methyl cyclohexene dan toluene) terbentuk lebih cepat dibandingkan produk ethyl phenol (ethyl cyclohexane, ethyl benzene dan ethyl cyclohexene). Toluene dan methyl 
cyclohexane ditemukan menjadi produk dominan untuk methyl phenol dengan intensitas peak yang lebih besar sedangkan ethyl benzene dan ethyl cyclohexane adalah produk utama ethyl phenol.

Methyl cyclohexanol yang merupakan salah satu produk methyl phenol, seperti telah dijelaskan pada literatur, ternyata tidak terdeteksi menggunakan metode ini.

Selanjutnya, ditunjukkan pula bahwa hidrogenasi butyl benzene menghasilkan hanya butyl cyclohexane sebagai produk turunan. Naphtalene dihidrogenasi menjadi decaline (cisdan trans-) dan tetraline, dimana tetraline sebagai produk dominan. Produk turunan butyl benzene muncul sebelum produk naphthalene. Hal ini mengindikasikan laju reaksi hidrogenasi butyl benzene lebih cepat dibandingkan naphthalene.

Sedangkan, 1,2,3,4-tetrahydroquinoline yang merupakan produk pada proses hidrodenitrogenasi quinoline (hidrogenasi cincin N) tak terdeteksi menggunakan FID . Tetapi, produk ini terdeteksi dengan peak tertinggi, seperti dikonfirmasikan oleh analisis NPD. Decahydroquinoline (cis- dan trans-) dan propyl aniline juga muncul dalam produk, tetapi $5,6,7,8$ tetrahydroquinoline dan propyl cyclohexylamine tidak terdeteksi untuk semua variasi temperatur baik menggunakan detektor FID maupun konfirmasi peak dari NPD. Tumpang tindih antara peak untuk methyl aniline dengan peak untuk tetraline juga ditemukan dalam kasus ini. Propyl cyclohexane, propyl benzene dan propyl cyclohexene adalah produk hidrogenolisis amine, dimana muncul setelah produk hydrodeoxygenation methyl dan ethyl phenol.

Lima produk turunan terdeteksi dari hidrogenasi phenanthrene antara lain adalah perhydrophenanthrene, 9,10 dihydrophenanthrene, 1,2,3,4-tetrahydrophenanthrene dan dua spesies octahydrophenanthrene. Hydrocracking juga terjadi, seperti ditunjukkan dalam pembentukan biphenyl.

Dalam kasus ini, hidrogenasi pyrene, yang muncul pada retensi waktu yang paling lama, 4,5-dihydropyrene, 4,5,9,10-tetrahydropyrene, dua spesies decahydropyrene dan dua spesies hexahydropyrene terdeteksi, sedangkan perhydropyrene tidak terdeteksi.

\section{KESIMPULAN}

Secara umum dari hasil identifikasi ini dapat disimpulkan bahwa reaksi utama yang terjadi adalah hidrogenasi, hidrodenitrogenasi dan hidrodeoksigenasi. Dimana, hidrodeoksigenasi methyl phenol and ethyl phenol terjadi lebih cepat dibandingkan dengan reaksi hydroprocessing yang lain seperti hidrodenitrogenasi quinoline dan hidrogenasi aromatis (butyl benzene, naphthalene, phenanthrene dan pyrene).

$\mathrm{Hal}$ ini mengindikasikan bahwa reaksi hidrodeoksigenasi atau pemutusan ikatan C-O terjadi sangat cepat, dimana alkylcyclohexanol tak terdeteksi pada produk minyak. Reaksi hidrodenitrogenasi atau pemutusan ikatan C-N terjadi lebih lambat, tetapi senyawa mengandung nitrogen menghilang lebih cepat akibat selektif adsorpsi pada katalis. Sedangkan reaksi hidrogenasi mono-aromatis terjadi lebih cepat dibandingkan poly-aromatis

\section{DAFTAR PUSTAKA}

Aubert C, et. al., 1988. Journal of Catalysis, 112, 12-20.

Anderson J.R., 1996. Catalysis : Science and Technology, 11, 130.

Eijsbouts S, et. al., 1991. Journal of Catalysis, 127, 605-618.

Hanif, M., 1999. Upgrading of Coal-Derived Liquid. Technical Report, NIMC, Tsukuba, Japan.

Hanif, M., 2002. Pengujian Unjuk Kerja Katalis Ni-W/Alumina Pada Upgrading Minyak Batubara Cair. Seminar Nasional Teknik Kimia UNDIP, Semarang, hal. B.6.1-B.6.6.

Lee, C.L, et. al., Journal of Catalysis, 1987. 884, 325-331.

Moreau, et.al., 1988. Journal of catalysis 112, 411.

Odebunmi, E.O, et. al., 1983. Journal of Catalysis, 80, 56-64.

Sugimoto, Y. dan Hanif, M., 2000. Upgrading of Coal-Derived Liquid over Ni-W/Alumina. Japan Institute of Energy, hal. 65-68. 